\title{
Data glitches delay observation satellite
}

[WASHINGTON] Software problems will delay the long-awaited launch of the first major satellite in the US space agency NASA's Earth Observing System (EOS), a network of at least three large spacecraft and many smaller ones designed to study the Earth as an integrated system.

The AM-1 spacecraft — which carries US, Japanese and Canadian sensors for monitoring clouds, ice, land and water - was to have been launched in June, but will now remain grounded until at least December.

The problem is with a segment of the troubled EOS data system known as the EOSDIS, one of the most complex software engineering projects ever attempted. The $\$ 2$ billion EOSDIS is designed to handle unprecedented volumes of data from a variety of orbiting sensors over a decade or more, and to format the data for a wide range of users, from scientists to the general public.

Although the system passed an important test of its science data processing segment last summer (see Nature 389, 108; 1997), other difficulties have continued. One problem area is the software's Flight Operations Segment (FOS), designed to control and monitor the health of all EOS spacecraft and to schedule onboard activities such as instrument pointing.

NASA had hoped that bugs in earlier versions of the FOS would be corrected in a new version which was delivered last month by the Lockheed Martin Corporation. But some of the old problems remain, and new ones have appeared, according to EOSDIS

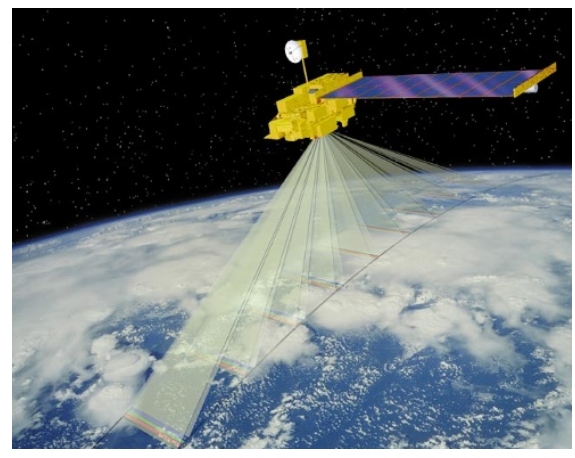

Still grounded: A computer-generated image of the EOS AM-1 spacecraft orbiting Earth.

project manager Rick Obenschain of the NASA Goddard Space Flight Center in Maryland.

If the FOS cannot be fixed in time for the AM-1 launch, the space agency is considering adapting commercially available software similar to that used for the recently launched Tropical Rainfall Measuring Mission and the forthcoming Landsat 7 which also has slipped from a July launch to at least February, due to a power supply problem with its main instrument.

Any off-the-shelf alternative would not be a full replacement for the FOS, says Obenschain, and would be a one-time-only fix. It is also unlikely that it would be ready by December, he says.

The EOSDIS is "meant to be everything to everybody", he says, which may be its biggest problem. In retrospect, says Obenschain, it was "probably not a very good intent" to design a single, massive data sys- tem to handle all the needs of all EOS spacecraft (more than two million lines of computer code have been written already).

The project has suffered major delays, attrition rates as high as 38 per cent among its software engineers, and perhaps now an insurmountable problem with the FOS for AM-1.

Scientifically, the expected slip in the schedule will have little impact. Byron Tapley of the University of Texas, who will take over next week as chair of the science executive committee for the EOS Investigators Working Group, says there will be "no major Earth-shaking loss in science opportunity" if the delay lasts only a few months.

But the future of the EOSDIS may be on the line. Several outside advisory groups have recommended that NASA should switch to a distributed or 'federated' system, whereby many different organizations would supply the research community with data from one or two EOS instruments.

In December the space agency picked two dozen Earth Science Information Partners, who will have three to five years to develop and distribute prototype data products for scientists and other users.

Meanwhile the seven large, centralized data archives organized under the current EOSDIS architecture are being reviewed by a committee of the National Academy of Sciences. The committee, which is chaired by Francis Bretherton of the University of Wisconsin, meets in Washington this week, and hopes to report by the end of the summer.

\section{German sex killings prompt decision to create a DNA database}

[MUNICH] Germany's federal criminal office is to introduce a central DNA database for sex offenders, convicted murderers and others who commit serious crimes, including members of house-breaking rings. The minister of the interior, Manfred Kanther, approved the plan last week.

The move follows a series of largely unsolved sex killings of children in the past few months in Germany. Political pressure to introduce a DNA database grew particularly strong after the most recent case, the murder of a 13-year-old girl in Lower Saxony last month.

Rapid advances in DNA analysis and bioinformatics have made DNA databases invaluable to forensic scientists. Such databases are already used in the United States, Britain, the Netherlands and Austria, and pressure is growing for similar moves in France (see Nature 392, 430; 1998). But Germany has held back until now, mainly because of concern about privacy and data protection issues.

Police in Germany already use genetic fingerprinting based on samples of hair, tissue, saliva or sperm found on the bodies or clothes of victims. But they have not had the opportunity to compare the genetic profile of such samples with data held in a central DNA database.

In the case of the recent Lower Saxony murder, police had to request saliva samples from all the 18,000 men between the ages of 18 and 30 in the region in which they believe the murderer lives to allow a comparison with the murderer's genetic fingerprint.

The samples are being analysed in police laboratories in Hanover. The procedure has been criticized for its high costs and relatively low likelihood of success, as donations are voluntary and the police are relying more on being able to rule out individuals than on identifying the murderer directly.

"Germany can no longer afford to do without an instrument that has proved an efficient criminological tool," says Detlef Dauke, a spokesman for the Ministry of the Interior.

The DNA database will be built up gradually. According to Dauke, the technical equipment is already available at the federal criminal office. Germany's 16 Länder (states), which are responsible for policing, will start to transmit existing DNA data immediately.

It remains to be decided for which crimes compulsory production of a DNA sample will be required and for how long samples will be stored. And it is still unclear whether the operation of the database will need to be backed by new legislation, if its data are to be acceptable as legal evidence in a trial.

But there is a broad consensus that the database will help to speed the rate at which serious crimes are solved, and will help to lead to the immediate ruling out of innocent suspects.

Quirin Schiermeier 